\title{
Simple measures of climate, soil properties and plant traits predict national scale grassland soil carbon stocks
}

Article

Accepted Version

Manning, P., de Vries, F. T., Tallowin, J. R. B., Smith, R., Mortimer, S. R., Pilgrim, E. S., Harrison, K. A., Wright, D. G., Quirk, H., Benson, J., Shipley, B., Cornelissen, J. H. C., Kattge, J., Bonisch, G., Wirth, C. and Bardgett, R. D. (2015) Simple measures of climate, soil properties and plant traits predict national scale grassland soil carbon stocks. Journal of Applied Ecology, 52 (5). pp. 1188-1196. ISSN 0021-8901 doi: https://doi.org/10.1111/1365-2664.12478 Available at https://centaur.reading.ac.uk/41210/

It is advisable to refer to the publisher's version if you intend to cite from the work. See Guidance on citing.

Published version at: http://www.journalofappliedecology.org

To link to this article DOI: http://dx.doi.org/10.1111/1365-2664.12478

Publisher: Wiley-Blackwell

All outputs in CentAUR are protected by Intellectual Property Rights law, including copyright law. Copyright and IPR is retained by the creators or other copyright holders. Terms and conditions for use of this material are defined in the End User Agreement. 


\section{www.reading.ac.uk/centaur}

\section{CentAUR}

Central Archive at the University of Reading

Reading's research outputs online 
1 Simple measures of climate, soil properties and plant traits predict national

2 scale grassland soil carbon stocks

3

4

Authors: Pete Manning ${ }^{\mathrm{a}^{*}}$, Franciska T. de Vries ${ }^{\mathrm{b}, \mathrm{c}}$, Jerry R.B. Tallowin ${ }^{\mathrm{d}}$, Roger Smith ${ }^{\mathrm{e}}$, Simon R. Mortimer ${ }^{\mathrm{f}}$, Emma S. Pilgrim ${ }^{\mathrm{d}}$, Kate A. Harrison ${ }^{\mathrm{c}}$, Daniel G. Wright ${ }^{\mathrm{c}}$, Helen Quirk ${ }^{\mathrm{c}}$, Joseph Benson $^{\mathrm{e}}$, Bill Shipley ${ }^{\mathrm{g}}$, Johannes H.C. Cornelissen ${ }^{\mathrm{h}}$, Jens Kattge ${ }^{\mathrm{i}}$, Gerhard Bönisch ${ }^{\mathrm{i}}$, Christian Wirth ${ }^{\mathrm{i}}$ and Richard D. Bardgett ${ }^{\mathrm{b}, \mathrm{c}}$.

Affiliations: aniversity of Bern, Institute of Plant Sciences, Altenbergrain 21, CH-3013 Bern, Switzerland. ${ }^{b}$ Faculty of Life Sciences, Michael Smith Building, The University of Manchester, Oxford Road, Manchester M13 9PT, UK, ${ }^{c}$ Lancaster Environment Centre, Lancaster University, Lancaster LA1 4YQ, UK. ${ }^{\mathrm{d}}$ Rothamsted Research, North Wyke,

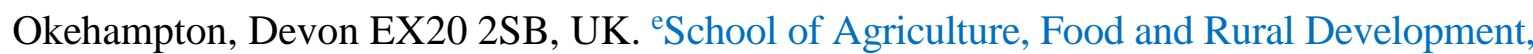
University of Newcastle, Newcastle upon Tyne, NE1 7RU, UK. ${ }^{\mathrm{f} C e n t r e ~ f o r ~ A g r i-~}$

Environmental Research, University of Reading, RG6 6AR, UK. 'Département de biologie, Université de Sherbrooke, Sherbrooke (Qc) J1K 2R1, Canada. 'hystems Ecology, Department of Ecological Science, VU University, 1081 HV Amsterdam, The Netherlands. ${ }^{\mathrm{i}}$ Max Planck Institute for Biogeochemistry, 07745 Jena, Germany.

*Corresponding author: pete.manning@ips.unibe.ch, Tel: +41 31 6314926, Fax: +41 31 6314942 E-mail addresses:franciska.devries@manchester.ac.uk, jerry.tallowin@ rothamsted.ac.uk, s.r.mortimer@ reading.ac.uk, emma.dolphin@virgin.net, kath@ceh.ac.uk, dgwr@ ceh.ac.uk, h.quirk@lancaster.ac.uk, bill.shipley@usherbrooke.ca, j.h.c.cornelissen@vu.nl, jkattge@bgc-jena.mpg.de, boenisch@bgc-jena.mpg.de, 
27 Type of paper: Standard paper

28 Running title: predicting grassland soil carbon stocks

29 Word count (total): 6988

30 Summary: 303

$31 \quad$ Main text: 4781

32 Acknowledgements: 97

33 References: 1196

34 Tables and figure legends: 341

35 No. tables: 1

36 No. Figures: 3

37 No. References: 46

38

39

40

41

42

43

44 


\section{Summary:}

1. Soil carbon (C) storage is a key ecosystem service. Soil C stocks play a vital role in soil fertility and climate regulation, but the factors that control these stocks at regional and national scales are unknown, particularly when their composition and stability are considered. As a result, their mapping relies on either unreliable proxy measures or laborious direct measurements.

2. Using data from an extensive national survey of English grasslands we show that surface soil $(0-7 \mathrm{~cm}) \mathrm{C}$ stocks in size fractions of varying stability can be predicted at both regional and national scales from plant traits and simple measures of soil and climatic conditions.

3. Soil C stocks in the largest pool, of intermediate particle size $(50-250 \mu \mathrm{m})$, were best explained by mean annual temperature (MAT), soil $\mathrm{pH}$ and soil moisture content. The second largest $\mathrm{C}$ pool, highly stable physically and biochemically protected particles $(0.45-50 \mu \mathrm{m})$, was explained by soil $\mathrm{pH}$ and the community abundance weighted mean $(\mathrm{CWM})$ leaf nitrogen $(\mathrm{N})$ content, with the highest soil $\mathrm{C}$ stocks under $\mathrm{N}$ rich vegetation. The $\mathrm{C}$ stock in the small active fraction $(250-4000 \mu \mathrm{m})$ was explained by a wide range of variables: MAT, mean annual precipitation, mean growing season length, soil $\mathrm{pH}$ and CWM specific leaf area; stocks were higher under vegetation with thick and/or dense leaves.

4. Testing the models describing these fractions against data from an independent English region indicated moderately strong correlation between predicted and actual values and no systematic bias, with the exception of the active fraction, for which predictions were inaccurate.

5. Synthesis and Applications: Validation indicates that readily available climate, soils and plant survey data can be effective in making local- to landscape-scale (1-100,000 
$\mathrm{km}^{2}$ ) soil C stock predictions. Such predictions are a crucial component of effective management strategies to protect $\mathrm{C}$ stocks and enhance soil $\mathrm{C}$ sequestration.

Keywords: carbon storage, carbon sequestration, community weighted mean, $\mathrm{pH}$, particle size fractions, soil carbon, soil organic matter.

\section{Introduction}

Soil carbon (C) stocks exceed those in both vegetation and the atmosphere by 2-3 times, and play a vital role in climate regulation and the maintenance of soil fertility (Trumper et al. 2009), but these stocks vary by orders of magnitude over regional and national scales, even within a single ecosystem type (Bellamy et al. 2005: Carey et al. 2008). Presently, their mapping either relies upon proxy measures that are often poor estimates of actual soil C stocks, particularly at local scales (Jones et al. 2005; Eigenbrod et al. 2010; Stevens et al. 2013), or direct measurements, which are expensive and laborious (Bellamy et al. 2005; Carey et al. 2008). Models are also used to predict soil C, but these are typically used to make largescale or scenario based projections and not fine-scale, extensive soil C stock mapping (Schimel et al. 1994; Smith et al. 2005).

Improved predictions of soil $\mathrm{C}$ stocks should be possible if the factors determining national, regional and local distributions of soil $\mathrm{C}$ are better understood. It has long been known that soil C is controlled by a wide range of factors (Jenny 1941; Schimel et al. 1994), that can be viewed as forming a 'hierarchy of controls' (Diaz et al. 2007, De Vries et al. 2012), which impact the basic processes of plant growth and organic matter decomposition and stabilisation. At the apex of the hierarchy is climate, which controls the metabolism of 
plants, fauna and microbes (Burke et al. 1989. Schimel et al. 1994; Conant et al. 2011) and determines rates of rock weathering (White 1997), thus influencing soil properties. The next level in the hierarchy are soil abiotic properties, such as texture and $\mathrm{pH}$, which are largely controlled by underlying geology and processes of weathering (Jenny 1941; White 1997), and which in turn influence soil $\mathrm{C}$ storage by affecting plant growth and microbial activity (Pietri and Brookes 2008; Schmidt et al. 2011). At a local level, soil C storage is also strongly affected by land use type and intensity, which has an array of impacts on soil $\mathrm{C}$ cycling (Conant, Paustain \& Elliot 2001; Smith 2014). Moreover, climate, soil properties and management all influence the composition and growth of the vegetation, which in turn affects the amount and chemistry of plant inputs, and the turnover of soil organic matter (SOM) (Cornwell et al. 2008; De Deyn, Cornelissen \& Bardgett. 2008; De Vries et al. 2012).

Although it has long been acknowledged that the above factors are the primary regulators of soil $\mathrm{C}$ storage, their interdependence makes estimating their relative importance challenging. While some studies emphasise the importance of soil physical and chemical properties (Christensen 2001; Schmidt et al. 2011), there is also evidence that plant community composition plays a significant role (De Deyn, Cornelissen, \& Bardgett 2008). While the importance of vegetation properties has long been recognised, and is represented in C models (Parton et al. 1993, Smith et al. 2005), they have typically been viewed only from a tissue chemistry perspective, and the importance of other plant traits have rarely been considered. This may be an oversight as plant species vary along a 'fast-slow' traits axis, which distinguishes between fast growing species with rapidly decomposing litters and fast tissue turnover times and their opposite (Reich 2014). Accordingly, if species effects on ecosystem function are proportional to their biomass (Grime 1998), then community abundance weighted means $(\mathrm{CWM})$ of species-level traits may explain variation in soil $\mathrm{C}$ storage and sequestration (Garnier et al. 2004). In line with this prediction, recent work shows 
that CWM trait measures can explain ecosystem-level variation in plant production,

decomposition, photosynthesis, respiration and soil $\mathrm{C}$ concentration, and microbial community composition (Garnier et al. 2004; Diaz et al. 2007, De Vries et al. 2012; Grigulis et al. 2013; Everwand et al. 2014). While such studies point to the tractability of scaling up from traits of individual plants to ecosystem properties, the capacity of this approach to predict soil $\mathrm{C}$ at spatial scales large enough to matter to $\mathrm{C}$ stock management is unknown.

Another drawback of existing methods of soil C stock prediction is that they typically predict only the total amount of soil C and not its composition (Jones et al. 2005; Stevens et al. 2013). Soil C is diverse in its chemistry and interactions with soil particles, and as a result soil C particles vary greatly in their turnover rates (Trumbore 2000, Schmidt et al. 2011). Accordingly, soil C storage and sequestration is determined not just by the total soil C pool, but also by the half-lives of soil $\mathrm{C}$ components, which can be categorised into pools of varying stability (Schimel et al. 1994: Trumbore 2000). Such pools are arbitrarily defined but are represented in modern soil $\mathrm{C}$ models. Measuring them is inherently difficult, so we lack reliable baseline data on the amount of $\mathrm{C}$ in these pools for most of the Earth's land surface. While isotopic techniques $\left({ }^{13} \mathrm{C}\right.$ and ${ }^{14} \mathrm{C}$ ) can be employed (e.g. Trumbore 2000; Marschner $e t$ al. 2008), their use is impractical in large-scale surveys given their high cost and requirement for specialist equipment and personnel. An alternative approach is to use more readily measurable size and density fractions, which broadly correspond to $\mathrm{C}$ turnover times (Christensen 2001; Marschner et al. 2008). Fresh C inputs are predominantly found in large particles that constitute the active fraction, which turns over within months to a few years, making it the source of most soil $\mathrm{C}$ fluxes. In contrast, $\mathrm{C}$ found in particles of intermediate size is typically humified organic matter $(\mathrm{OM})$ that turns over on decadal timescales; while small and dense soil particles of physically and chemically protected soil comprise the stable C fraction. This typically turns over on the scale of centuries to millennia and is crucial to soil 
C sequestration (Schimel et al. 1994; Trumbore 2000; Christensen 2001). While relationships between many of the aforementioned drivers and total soil carbon over large scales have been quantified previously (e.g. Burke et al. 1989), their relationship with different C size fractions has received very little attention (Evans, Burke \& Lauenroth et al. 2011). The relative importance of the aforementioned drivers in determining stable soil $\mathrm{C}$ may differ from those controlling rapid turnover fractions, and this could explain discrepancies between studies of soil C drivers, which typically focus upon total soil C. different $\mathrm{C}$ fractions in the surface soil $(0-7 \mathrm{~cm})$ of grassland. This was done for two reasons: a) to identify the potential abiotic and biotic (i.e. plant traits) determinants of these fractions at large spatial scales; and b) to assess the potential for using a combination of simple plant trait and abiotic measures that are readily available to surveyors to predict these soil $\mathrm{C}$ stocks, i.e. to identify potential variables to be used in pedotransfer functions and/or ecological production functions for these fractions. To do this we generated linear mixed-effects statistical models describing national scale patterns of surface soil $\mathrm{C}$ in different size fractions across a wide spectrum of the soil and climatic conditions found across England, and a broad range of grassland types (including calcareous, mesotrophic, wet and acid, Rodwell 1992). These quantified the relative importance and predictive capacity of several abiotic factors and various CWM plant traits with strong hypothetical or known links soil C cycling (De Deyn, Cornelissen, \& Bardgett 2008). We hypothesised that stocks of the active soil C fraction are best predicted by the drivers of plant inputs to soil and the decomposability of these inputs (e.g. climate and plant traits), while the stable fraction is better explained by soil physical and chemical properties (e.g. soil texture and $\mathrm{pH}$ ). We focussed on grasslands because they cover $\sim 30 \%$ of the Earth's land surface and store $\sim 23 \%$ of the global terrestrial ecosystem C stock 
169

170

171

172

173

174

175

176

177

178

179

180

181

182

183

184

185

186

187

188

189

190

191

192

performed, they cover $36 \%$ of the land surface and contain an estimated $\sim 32 \%$ of national soil C stocks (Ostle et al. 2009).

\section{Materials and Methods}

\section{GRASSLAND SURVEY}

This work was conducted as part of a broader investigation aimed at quantifying relationships between agricultural intensification, botanical composition and soil properties, including microbial community composition, in temperate grasslands (De Vries et al. 2012). We sampled from twelve English regions during June and July 2005 (see Fig.1). Within each region there were five sites, each containing three fields, but subject to three broad management regimes: unimproved (U) and often designated as SSSI (Site of Special Scientific Interest), semi-improved (SI) or improved (I) grassland, resulting in a total of 180 fields (Fig. S1 in Supporting Information). The survey represented the broad habitat classifications of acid (33 fields), calcicolous (42 fields), mesotrophic (81 fields) and wet grasslands (24 fields), the main grassland types in the UK (Rodwell 1992), and fields were allocated to land management intensity categories based on consultation with farmers and land managers, and expert opinion. This process also ensured that adjacent fields were of similar soil type and topography. Typically, unimproved grasslands receive $<25 \mathrm{~kg} \mathrm{~N} \mathrm{ha}^{-1} \mathrm{y}^{-1}$ and are lightly grazed by livestock and cut annually for hay, whereas semi-improved and improved grasslands receive $25-50 \mathrm{~kg} \mathrm{~N} \mathrm{ha}^{-1} \mathrm{y}^{-1}$ and >100 $\mathrm{kg} \mathrm{N} \mathrm{ha}^{-1} \mathrm{y}^{-1}$, respectively, and are subject to higher grazing pressures and more frequent cutting for silage (Critchley, Fowbert \& Wright 2007). This broad classification of grasslands has been used widely (e.g. De Vries et 
al. 2012; Grigulis et al. 2013), and reflects the typical grassland farming systems that are found across the United Kingdom and other parts of Europe (Rodwell 1992).

There were many different plant community types present in the more botanically

diverse unimproved grasslands, but the improved categories were mainly the Lolium perenne

(L.) dominated MG6 and MG7 communities of the UK's National Vegetation Classification

(Rodwell 1992). Within each field, percentage cover of each plant species was visually

estimated from three random $1 \mathrm{~m}^{2}$ quadrats within a $25 \times 25 \mathrm{~m}$ plot of homogeneous

200

201

202

203

204

205 vegetation. These three cover values were averaged to obtain field level abundance estimates. Within each quadrat, five random $2 \mathrm{~cm}$ diameter $7 \mathrm{~cm}$ deep soil cores were taken and pooled. The use of $7 \mathrm{~cm}$ deep cores follows the UK's Department of Environment, Food and Rural Affairs (DEFRA) recommended sampling depth for assessment of soil abiotic properties in permanent grassland (DEFRA 2010), and was selected to capture the zone of soil most influenced by plant traits, and of greatest $\mathrm{C}$ content relative to sub-surface soil. We recognise that significant soil C stocks are found at depth in grasslands (Jobbagy and Jackson 2000), but sampling the whole soil profile was beyond the scope of this study, especially given the comprehensive suite of vegetation and soil properties measured.

\section{SOIL ANALYSIS}

Soil samples were sieved (4 mm), homogenised and air-dried, and analysed for moisture content, total C and pH, using standard methods (see Allen 1989 and Appendix A in Supporting Information for methods). Standardized wet sieving (De Deyn et al. 2011) was then used to separate the soil particles and the $\mathrm{C}$ within them into the active $(250-4000 \mu \mathrm{m})$, intermediate $(50-250 \mu \mathrm{m})$ and stable fractions $(0.45-50 \mu \mathrm{m})$ (see Appendix A. for details). To 
calculate soil C stocks on a per-area basis bulk density (BD) was calculated from core volume and dry soil weight after removing all stones and roots $>3 \mathrm{~mm}$ diameter. It is possible that black C (charcoal) and inorganic C was present in our samples, though the proportion of these factions is likely to be small (see appendix A). Soil texture was classified by expert judgment and transformed into clay-silt-sand percentages using the central point of each category of the triangular classification developed by the Soil Survey of England and Wales (Hodgson 1997).

\section{CLIMATE DATA}

Both long-term climate data from Met Office UKCP09 databases (Jenkins, Perry \& Prior 2009) and the grassland survey data were assigned to $5 \times 5 \mathrm{~km}$ grid cells. Mean annual temperature (MAT) and mean annual precipitation (MAP) were calculated from monthly data from 1981-2006. Mean growing season length (MGSL) values were taken from the UKCP09 database containing monthly values from 1961-2003 and calculated as the number of days bounded by a daily temperature mean $>5{ }^{\circ} \mathrm{C}$ and $<5{ }^{\circ} \mathrm{C}$ after 1 st July for more than five consecutive days. Mean growing degree days (MGDD) was the day-by-day sum of the mean number of degrees by which air temperature exceeded $5.5^{\circ} \mathrm{C}$. It was calculated using the mean of values from 1961-2006. The differences in time periods between these measures reflect data availability in the UKCP09 database.

\section{PLANT TRAIT DATA}


Plant species composition data were combined with database values of plant traits to give

240 field level CWMs for plant traits with hypothetical links to soil processes (Garnier et al. 2004;

241 Diaz et al. 2007; De Deyn, Cornelissen, \& Bardgett. 2008, De Vries et al. 2012). To do this

242 trait values were assigned to all plant species occurring in the 180 fields sampled and plant 243 cover was used as the CWM weighting measure. Values for leaf dry matter content (LDMC)

244 were taken from a published account of plant species in northern England (Grime, Hodgson \&

245 Hunt 2007). Values for specific leaf area (SLA), relative growth rate (RGR), and leaf nitrogen

246 content (leaf N) were obtained from the TRY database (Kattge et al. 2011), which contains

247 trait data from a wide range of authors and environments. See Appendix A for details of trait 248 measurement and justification of trait choice.
The grassland survey, climate and trait data were combined to form a single dataset (see Table

\section{STATISTICAL MODELLING}

S1 to see the range of conditions covered) that was used to parameterise and test the likelihood of competing mixed-effects statistical models according to a model selection procedure (Pinheiro and Bates 2000). A separate model was created to describe each soil C fraction as well as total $\mathrm{C}$. Our model selection approach involved adding explanatory variables in fixed sequential order a according to our hypothesised 'hierarchy of controls' (Appendix A, Diaz et al. 2007). The process started with variables describing climatic conditions (MAP, MAT, MGSL, MGDD), then added physical and chemical soil properties that are driven mainly by underlying geology and local hydrology (soil $\mathrm{pH}$, sand silt and clay content and soil moisture). The third set of terms was linked to management. Here, contrasts were made between three competing management terms, which either had three levels U, SI 
and I or two, with either SI and U or SI and I merged. Finally we added trait CWMs to estimate plant functional trait effects. CWM's for RGR, SLA, LDMC and leaf N were placed in the model in all combinations of one and two traits. Although microbial data were available (De Vries et al. 2012) they were not used to predict C stocks as they are not readily measurable by most surveyors. All models were linear mixed-effects models with a random effect for site to account for the spatial clustering of triplicate fields. Mixed models were fitted using maximum likelihood and the lme function of the statistical software $\mathrm{R}$ version 2.11.1 (Pinheiro and Bates 2000). Throughout the modelling process quadratic terms were used when the optimum of biological activity occurs at intermediate levels (i.e. for temperature, $\mathrm{pH}$, and moisture). See appendix A and Table S2 for details.

The explained variance of the final model was calculated as the $r^{2}$ when fitting a linear regression to the actual data, with the predicted values of the model as the explanatory variable. To estimate the variance explained by the fixed effects, we used the method of Nakagawa and Schielzeth (2013), which partitions explained variance by comparing the fit of model predictions to the data when these terms are absent from the model to calculate a 'marginal $\mathrm{R}^{2}$ ' $\left(\mathrm{R}^{2} \mathrm{M}\right)$. We also used this technique to estimate the proportion of unique (total) variance explained by each class of variable in the model (soil, climate, plant traits). The importance of each variable in the model was also estimated by observing AIC change $(\Delta \mathrm{i})$ on deletion.

\section{MODEL VALIDATION}

To validate the fitted models we collected new data for all the variables retained in the models (Tables 1 and 2) in 20 fields in the county of Northumberland, England in summer 2012. This 
is a separate region to the north east of the original 12 (Fig. 1). Methodology was identical to before with the exception of site selection. In this case we intentionally chose sites covering a wide range of the predictor variables found in the original dataset, but excluded sites from outside these ranges to avoid extrapolation (Table S1), because our models were not mechanistic. To validate the fitted models, predictor variable values for the Northumberland sites were fed into the fitted models to produce estimated values. These were then compared to actual values using Pearson's correlation and paired t-tests.

\section{Results}

Total soil $\mathrm{C}$ stock to $7 \mathrm{~cm}$ depth was best described (Table $1, \mathrm{~S} 3$; explained variance $(\mathrm{EV})=$ $74.2 \%, \mathrm{R}^{2} \mathrm{M}=26.9 \%$ ) by a quadratic relationship for mean annual temperature (MAT) (Fig. 2a), with $\mathrm{C}$ stocks being lowest at intermediate temperatures of $\sim 8.5^{\circ} \mathrm{C}$. This temperature effect accounted for $13.7 \%$ of unique variance. Variation in total soil $\mathrm{C}$ stock was also related to soil $\mathrm{pH}$, with stocks being lowest at intermediate $\mathrm{pH}$ values of $\sim 6$ (Fig. 2a) (quadratic relationship). Finally, soil $\mathrm{C}$ stocks were related to soil moisture and maximal at moisture levels of $\sim 100 \%$, on a dry soil weight basis. Together these soil terms accounted for $15.2 \%$ of unique variance.

Models explaining the three component fractions differed greatly in the variables they contained, indicating that each is controlled by different factors. The active fraction (4000$250 \mu \mathrm{m}$ ) (Fig. 3, Table 1, S4) accounted for $11.1 \%$ of total C stocks across grasslands, and the model describing it accounted for $41.0 \%$ of its variation $\left(\mathrm{R}^{2} \mathrm{M}=37.6 \%\right)$ and contained five variables, each strongly linked to plant productivity and litter decomposition. The most important of these were quadratic relationships with MAT (Fig. 2b) and MAP; stocks of this 
$\mathrm{C}$ fraction were highest in cold, wet conditions. This pool was also positively associated with mean growing season length (MGSL), presumably via higher net primary productivity, and resulting inputs of $\mathrm{C}$ to soil (Table 1). Together, these climate factors accounted for $22.0 \%$ of unique variance. Soil $\mathrm{pH}$ accounted for $8.7 \%$ of unique variance and also displayed a quadratic relationship with the active $\mathrm{C}$ fraction, being greatest in acidic soils. Finally, we found that the active $\mathrm{C}$ fraction was predicted by the CWM of SLA; stocks were higher under vegetation with thick and/or dense leaves. This trait measure accounted for $4.3 \%$ of unique variance.

The intermediate fraction $(50-250 \mu \mathrm{m})$ represented $54.7 \%$ of total soil $\mathrm{C}$ stocks to $7 \mathrm{~cm}$ depth across grasslands (Fig. 3) and was described by a model that was very similar to that describing total $\mathrm{C}$ stocks $\left(\mathrm{EV}=78.4 \%, \mathrm{R}^{2} \mathrm{M}=19.9 \%\right.$, Table 1 , S5); the retained terms described quadratic relationships with MAT (Fig. 2c), soil moisture and pH (Fig. 2c). Stocks of this $\mathrm{C}$ fraction were lowest in soils of neutral grassland and at intermediate climates (MAT $\sim 9{ }^{\circ} \mathrm{C}, \mathrm{pH} \sim 6$ ). Of the retained variables climate terms were marginally more important (11.8\% unique variance) than soil terms (9.6\% unique variance).

The stable soil $\mathrm{C}$ fraction $(0.45-50 \mu \mathrm{m})$, which comprised $32.4 \%$ of the total $\mathrm{C}$ stocks across grasslands (Fig. 3), was not explained by climate or management variables. The model $\left(\mathrm{EV}=74.2 \%, \mathrm{R}^{2} \mathrm{M}=17.53 \%\right.$, Table $\left.1, \mathrm{~S} 6\right)$ indicated a strong and quadratic relationship with soil $\mathrm{pH}$, with the highest stocks being found in neutral and alkaline grassland soils (Fig 2d). C stocks in this fraction also increased subtly with increasing CWM leaf $\mathrm{N}$ content. This trait effect accounted for far less variance (1.9\% unique variance) than $\mathrm{pH}(14.16 \%$ unique variance).

Comparison of predicted and observed values of soil $\mathrm{C}$ stocks demonstrated that the fitted models made reasonably reliable predictions of observed stocks of total $\mathrm{C}$ and the 
intermediate and stable fractions but not the active fraction (Fig. S2). Correlations between predicted and observed values were $r=0.57-0.64$, and there was no significant difference between them (paired t-tests $P>0.05, \mathrm{t}=<2$, d.f. $=19$ ), with the exception of the active fraction $(r=0.03, P<0.05)$ (Table S7, Fig. S1).

\section{Discussion}

Our results indicate that regional and national patterns of $\mathrm{C}$ fractions in the surface soils of grasslands can be predicted using fairly simple measures of the abiotic environment and community-level plant traits. Reasonably accurate prediction of soil $\mathrm{C}$ stocks across broad gradients of soil and ecosystem types has been achieved previously using dynamic models (e.g. Parton et al. 1993) and proxy measures (Paruelo et al 1998; Jones et al. 2005). However, it has not, to our knowledge, been achieved for different size fractions of soil $\mathrm{C}$ within a single land use type, as shown here. The relationships identified here may not always be mechanistically causative because climate, management and underlying geology all directly affect soil C stocks whilst also selecting for different plant trait syndromes (De Vries et al. 2012), making trait measures an integrated measure of the environment. Nevertheless, all terms in the models accounted for unique variation, meaning that these relationships strongly indicate the primary regulators of these soil C fractions. Importantly, we found that several factors that influence soil $\mathrm{C}$ stocks at small scales, such as agricultural management (Conant, Paustain \& Elliot 2001) and soil texture (Christensen 2001), do not explain national patterns in $\mathrm{C}$ stocks at these shallow depths. In contrast, plant traits did explain the C stocks of certain fractions. The surprising lack of soil texture effects on soil $\mathrm{C}$ pools may be because soil $\mathrm{C}$ is controlled by soil physical properties that were not captured by our field assessment, e.g. 
mineral surface charges (Schmidt et al. 2011) and secondary and tertiary aspects of soil structure that determine the availability of $\mathrm{C}$ to decomposers, e.g. compaction, microaggregates and macropores (Christensen 2001). Alternatively, the lack of soil texture effects may be due to low data resolution or the rarity of clay rich soils sampled (Table S1). We also highlight that although plant traits explained a small proportion of variance their importance may be greater than it appears in our models, given their correlation with many of the other descriptor variables and their place at the base of our hierarchy of controls and modelling procedure.

Looking at each model in turn provides insight into the factors driving each pool and emphasises the need to view soil $\mathrm{C}$ as a heterogeneous material when attempting to understand its dynamics and meaningfully quantify $\mathrm{C}$ stocks. The active fraction model demonstrates that stocks in this fraction are highest where plant growth is high (high MAT and MGSL), but decomposition is possibly slow (low pH and high MAP) (Cornwell et al. 2008; Pietri and Brookes 2008). Despite a low overall model fit, there was, as hypothesised, a strong relationship with the CWM of SLA. Where vegetation possessed leaves that were thin and/or low density and lacked more slowly decomposing structural materials (Reich 2014), stocks of this fraction were lower (Fig. 2b), a finding that is consistent with previous studies linking SLA to litter decomposition rates (e.g. Garnier et al. 2004). The poor predictive capacity of our active fraction model may be due to the dynamic nature of this pool, which is highly variable seasonally (Christensen 2001). It may be better predicted by models in which plant production and decomposition are more explicitly defined.

Unlike the other $\mathrm{C}$ fractions the stable pool was not explained by climate, possibly because much of this $\mathrm{C}$ would have entered this pool and become stabilised in different climatic conditions to those experienced today. This finding is consistent with some largescale gradient studies, which show stable soil C stocks to be largely insensitive to temperature 
(Conant et al. 2011), although in other regions (e.g. Inner Mongolia) mineral associated C is the largest $\mathrm{C}$ pool and shows a strong relationship with climate (Evans, Burke \& Lauenroth 2011). In contrast, but in line with our hypotheses, the stable $C$ pool was strongly influenced by soil $\mathrm{pH}$. Higher stocks in more neutral and alkaline soils may reflect greater microbial processing of $\mathrm{SOM}$ in higher $\mathrm{pH}$ soils, resulting in greater transfer of $\mathrm{C}$ to chemically protected pools (Fornara et al. 2011). There was also a relatively small and unexpected effect of CWM leaf $\mathrm{N}$ content, which might be explained by $\mathrm{N}$ rich plant material reducing the need for 'microbial mining', a process where soil microbes decompose SOM to acquire N (Craine, Morrow \& Fierer 2007). Given that CWM leaf $\mathrm{N}$ is higher in improved, fertilised grasslands (De Vries et al. 2012), it might also reflect higher inorganic $\mathrm{N}$ availability in a more statistically parsimonious way than the deleted management term. Management was not retained in any of our models, and this may reflect the very broad categories used, which cover a range of fertilizer and mowing regimes, and grazing intensities. Gathering detailed and accurate data for such factors requires considerable effort and plant traits, which respond to all these factors, may act as a good proxy substitute for them.

Models describing the total $\mathrm{C}$ stocks and the intermediate fraction were extremely similar, which is unsurprising given that most soil $\mathrm{C}$ was in the intermediate fraction. The decline of soil $\mathrm{C}$ stocks at intermediate $\mathrm{pH}$ is likely caused by the balance of two contrasting processes: reduced decomposer activity and the accumulation of plant inputs in low $\mathrm{pH}$ conditions (Pietri and Brookes 2008), and greater transfer of $\mathrm{C}$ to the stable $\mathrm{C}$ fraction in more neutral and calcareous soils (Fornara et al. 2011). The moisture term in the total $\mathrm{C}$ model demonstrates that stocks peaked at soil moisture levels typical of waterlogged, or wet grasslands where soil microbial activity is low. The lack of plant trait terms in these models may reflect the fact that most older soil $\mathrm{C}$ has either undergone chemical and/or physical 
transformation into more complex forms, or because current plant community composition does not reflect its origin.

Previous studies have shown that regression models can predict soil $\mathrm{C}$ variation using climate and soil texture data at very large scales and within several continents $\left(>100,000 \mathrm{~km}^{2}\right)$ (Burke et al. 1989, Paruleo et al. 1998, but see Evans, Burke and Lauenroth 2011). Our findings indicate that a combination of plant trait data and simple climate and soil measures, can also help to predict regional and national scale soil $\mathrm{C}$ stocks $\left(1-100,000 \mathrm{~km}^{2}\right)$ in the surface soil, in a range of $\mathrm{C}$ pools of varying stability. It is possible that this approach could greatly improve regional and national level predictions of surface soil $\mathrm{C}$ stocks compared to current land cover proxy methods (Eigenbrod et al. 2010). Climate data are available for many parts of the world, soil $\mathrm{pH}$ can be measured quickly and with little equipment, and many countries produce regular national surveys of plant community composition (e.g. Carey et al. 2008). Furthermore, large international trait databases now exist (Kattge et al. 2011) and some traits, such as leaf $\mathrm{N}$, may also be predictable from remote sensing (Dahlin, Asner \& Field 2013). Our approach may also prove complementary to current soil C mapping approaches, which use a combination of dynamic models such as CENTURY (Parton et al. 1993) and RothC (Smith et al. 2005), direct measurements (Bellamy et al. 2005; Carey et al. 2008) and proxy measures (Jones et al. 2005; Eigenbrod et al. 2010), in two ways. First, it could be used to parameterise the starting conditions for soil C pools in models; and, second it could provide more extensive and fine-scale coverage than might be possible from direct measurement, e.g. for cases in which landowners seek to map soil C.

The large amount of variation captured by the random effects in our models is likely to represent site differences in geology and legacies of landscape history (e.g. land use and glaciation), which may already be captured in coarse scale soil surveys. The measures here could help refine these coarse maps using local scale-information about soils, climate and 
plant communities. Similarly, this approach could help refine existing models that use proxy measures with extensive geographic coverage (e.g. land cover and climate) (e.g. Jones et al. 2005; Smith et al. 2005, Paruelo et al. 1998), by improving the characterisation of existing relationships and including trait based vegetation measures that are general, more detailed and mechanistically informative. Such an approach requires extension to a wider range of soil depths, environmental conditions and ecosystem types before it can be widely applied. Nevertheless, our results show that it has great potential, especially given the urgent need for large-scale, cost effective and accurate soil $\mathrm{C}$ stock characterisation. Such information is a precursor for the inclusion of soil $\mathrm{C}$ into $\mathrm{C}$ trading schemes and improved ecosystem service management.

\section{Acknowledgements}

This work was funded by a DEFRA grant awarded to a consortium led by R.D.B. (BD1451). We thank landowners and farmers for site access and information, and A.E. Edwards, S.J. Harris, C. Lawson, D.A. Beaumont, and A.M. Murray for field and laboratory assistance. D. Millward, and S. Barlow performed the vegetation survey. We also thank R. Brand-Hardy, V. Brown, and the staff of Natural England, especially S. Peel, R. Jefferson and C. Pinchey. Finally, we thank MPI-BGC Jena, who host TRY, and the international funding networks supporting TRY (IGBP, DIVERSITAS, GLP, NERC, QUEST, FRB and GIS Climate).

\section{Data Accessibility}




\section{References}

458

459

Allen, S.E. (1989) The chemical analysis of ecological materials. Blackwell, London.

460

Bellamy, P.H., Loveland, P.J., Bradley, R.I., Lark, R.M. \& Kirk, G.J.D. (2005) Carbon losses 461 from all soils across England and Wales 1978-2003. Nature, 437, 245-248.

462

Burke, I.C., Yonker, C.M., Parton, W.J., Cole, C.V., Flach, K. \& Schimel, D.S. (1989)

Texture, climate, and cultivation effects on soil organic matter content in U.S. grassland soils. Soil Science Society of America Journal, 53, 800-805.

465

Carey, P.D. Wallis, S., Chamberlain, P.M., Cooper, A., Emmett, B.A., Maskell, L.C., et al. 466 (2008) Countryside Survey: UK Results from 2007. NERC/Centre for Ecology \& Hydrology, UK.

Christensen, B.T. (2001) Physical fractionation of soil and structural and functional 469 complexity in organic matter turnover. European Journal of Soil Science 52, 345-353.

470

Conant, R.T., Paustian, K. \& Elliot, E.T. (2001) Grassland management and conversion into 471 grassland: effects on soil carbon. Ecological Applications, 11, 343-355.

472 Conant, R.T., Ryan, M.G., Ågren, G.I. Birge, H.E., Davidson, E.A., Eliasson, P.E., et al. 473 (2011) Temperature and soil organic matter decomposition rates - synthesis of current 474 knowledge and a way forward. Global Change Biology, 17, 3392-3404. 
475 Cornwell, W.K., Cornelissen, J.H.C., Amatangelo, K., Cornelissen, J.H., Amatangelo, K. 476 Dorrepaal, E. et al. (2008) Plant species traits are the predominant control on litter 477 decomposition rates within biomes worldwide. Ecology Letters, 11, 1065-1071.

478 Craine, J.M., Morrow, C. \& Fierer, N. (2007) Microbial nitrogen limitation increases 479 decomposition. Ecology, 88, 2105-2133.

Critchley, C.N.R., Fowbert, J.A., Wright, B. (2007) Dynamics of species-rich upland hay 481 meadows over 15 years and their relation with agricultural management practices. Applied 482 Vegetation Science. 10, 307-314.

483

484

485

486

487

488

489

490

491

492

493

494

495

Dahlin K.M., Asner, G.P. \& Field, C.B. (2013) Environmental and community controls on plant canopy chemistry in a Mediterranean-type ecosystem. Proceedings of the National Academy of Sciences of the United States of America, 110, 6895-6900.

De Deyn, G.B., Cornelissen, J.H. \& Bardgett, R.D. (2008) Plant functional traits and soil carbon sequestration in contrasting biomes. Ecology Letters, 11, 516-531.

De Deyn, G.B., Shiel, R.S., Ostle, N.J. McNamara, N.P., Oakley, S., Young, I., et al. (2011) Additional carbon sequestration benefits of grassland diversity restoration. Journal of Applied Ecology, 48, 600-608.

Defra (2010) Fertiliser Manual (RB209), $8^{\text {th }}$ Edition. The Stationery Office, Norwich.

Díaz, S., Lavorel, S., de Bello, F., Quétier, F., Grigulis, K. \& Robson, T.M. (2007) Incorporating plant functional diversity effects into ecosystem service assessments. Proceedings of the National Academy of Sciences of the United States of America, 104, 20984-20689. 
Eigenbrod, F., Arnsworth, P.R., Anderson, B.J., Heinemeyer, A., Gillings, S., Roy, D.B. et al. (2010) The impact of proxy-based methods on the mapping of the distribution of ecosystem services. Journal of Applied Ecology 47, 377-385.

Evans, S.E., Burke, I.C., \& Lauenroth, W.K. (2011) Controls on soil organic carbon in Inner Mongolia, China: A cross-continental comparison of temperate grasslands. Global Biogeochemical Cycles, GCB3006, doi:10.1029/2010GB003945

Everwand G., Fry, E.L., Eggers, T., Manning, P (2014) Seasonal variation in the capacity for Plant trait measures to predict grassland carbon and water fluxes. Ecosystems, 17, 1095-1108.

Fornara, D.A., Steinbess, S., McNamara, N.P., Gleixner, G., Oakley, S., Poulton, P. R. et al. (2011) Increases in soil organic carbon sequestration can reduce the global warming potential of long-term liming to permanent grassland. Global Change Biology, 17, 1925-1934.

Garnier, E., Cortez, J., Billès, G. Navas, M.L., Roumet, C., Debussche, M. et al. (2004) Plant functional markers capture ecosystem properties during secondary succession. Ecology, 85, 2630-2637.

Grigulis, K., Lavorel, S., Krainer, U., Legay, N., Baxendale, C., Dumont, M., et al. (2013) Relative contributions of plant traits and soil microbial properties to mountain grassland ecosystem services. Journal of Ecology, 101, 47-57.

Grime, J.P. (1998) Benefits of plant diversity to ecosystems: immediate, filter and founder effects. Journal of Ecology, 86, 902-910.

Grime, J.P., Hodgson, J.G. \& Hunt, R. (2007) Comparative Plant Ecology. Castlepoint Press, Dalbeattie, UK.

Hodgson, J.M. (1997) Soil Survey Field Handbook. Cranfield University, Cranfield, UK. 
5371. Parton, W.J., Scurlock, J.M.O., Ojima, D.S. Gilmanov, T.G.,Scholes, R.J., Schimel, D.S., et Jenkins, G., Perry, M. \& Prior, J. (2009) The climate of the UK and recent trends. Met Office Hadley Centre, Exeter, UK.

Jenny, H. (1941) Factors of Soil Formation. Dover Publications, New York.

Jobbagy, E. G. \& Jackson. R. B. (2000) The vertical distribution of soil organic carbon and its relation to climate and vegetation. Ecological. Applications 10, 423-436.

Jones, R.J.A., Hiederer, R., Rusco, E. \& Montanarella, L. (2005) Estimating organic carbon in the soils of Europe for policy support. European Journal of Soil Science, 56, 655-671.

Kattge, J., Díaz, S., Lavorel, S., Prentice, I.C., Leadley, P., Bonisch, et al. (2011) TRY - a global database of plant traits. Global Change Biology, 17, 2905-2935.

Marschner, B., Brodowski, S., Dreves, A. Gleixner, G., Gude, A., et al. (2008) How relevant is recalcitrance for the stabilization of organic matter in soils. Journal of Plant Nutrition and Soil Science 171, 91-110.

Nakagawa, S. \& Schielzeth, H. (2013) A general and simple method for obtaining $\mathrm{R}^{2}$ from generalized linear mixed-effects models. Methods in Ecology and Evolution 4, 133-142.

Ostle, N.J., Levy, P.E., Evans, C.D. \& Smith, P. (2009) UK land use and soil carbon sequestration. Land Use Policy, 26S, 274-283.

Paruelo, J.M., Jobaggy, E.G., Sala, O.E., Lauenroth, W.K. \& Burke, I.C. (1998) Functional and structural convergence of temperate grassland and shrubland ecosystems. Ecological Applications 8, 194-206.

538 al. (1993) Observations and modeling of biomass and soil organic matter dynamics for the 539 grassland biome worldwide. Global Biogeochemical Cycles, 7, 785-809. 
540 Pietri, J.C.A. \& Brookes, P.C. (2008) Relationships between soil pH and microbial properties 541 in a UK arable soil. Soil Biology and Biochemistry, 40, 1856-1861.

542 Pinheiro, J.C. \& Bates, D.M. (2000) Mixed-Effects Models in S and S-PLUS. Springer543 Verlag, New York.

544 Reich, P.B. (2014) The world-wide 'fast-slow' plant economics spectrum: a traits manifesto. 545 Journal of Ecology 102, 275-301.

546 Rodwell, J.S. (Ed.). (1992) British Plant Communities, Volume 3. Grasslands and montane 547 communities. Cambridge University Press, Cambridge.

548 Schimel, D.S., Braswell, B.H., Holland, E.A., McKeown, R., Ojima, D.S., Painter, T.H. et al. 549 (1994) Climatic, edaphic, and biotic controls over storage and turnover of carbon in soils. 550 Global Biogeochemical Cycles, 8, 279-293.

551 Schmidt, M.W.I, Torn, M.S., Abiven, S, Dittmar, T., Guggenberger, G., Janssens, 552 I.A., Kleber, M. et al. (2011) Persistence of soil organic matter as an ecosystem property. 553 Nature, 478, 49-56.

554 Smith, J., Smith, P., Wattenbach, M., Zaehle, S., Hiederer, R., Jones, R. J. A., et al. (2005)

555 Projected changes in mineral soil carbon of European croplands and grasslands, 1990-2080. 556 Global Change Biology. 11, 2141-2152.

557 Smith, P. (2014) Do grasslands act as a perpetual sink for carbon? Global Change Biology. $558 \quad 20,2708-2711$.

559 Stevens, A., Nocita, M., Tóth, G., Montanarella, L. \& van Wesemael, B. (2013) Prediction of 560 soil organic carbon at the European scale by visible and near infrared reflectance 561 spectroscopy. PLoS One, 8, e66409. 
Trumbore, S. (2000) Age of soil organic matter and soil respiration: radiocarbon constraints on belowground C dynamics. Ecological Applications, 10, 399-411.

Trumper, K., Bertzky, B., Dickson, M., van der Heijden, G., Jenkins, M. \& Manning, P. (2009) The Natural Fix? The role of ecosystems in climate mitigation. United Nations Environment Programme, UNEP-WCMC, UNEP Rapid Response Assessment. Cambridge. De Vries, F.T., Manning, P., Tallowin, J.R.B., Mortimer, S.R., Pilgrim, E.S., Harrison, K.A. et al. (2012) Abiotic drivers and plant traits explain landscape-scale patterns in soil microbial communities. Ecology Letters 15, 1230-1239.

\section{Supporting information:}

Appendix A1 contains the following:

Details of soil $\mathrm{C}$ measurement and statistical modelling procures

Table S1. The mean and range of data used in model fitting and validation

Table S2. Parameter combinations fitted in the statistical modelling procedure

Table S3-S6. Model statistics for total soil carbon, and the active, intermediate and stable fractions

Table S7. Model validation comparison of predicted and actual values

Fig. S1. Demonstration of sampling strategy

Fig. S2. Comparison of soil carbon stocks predicted by the statistical models and actual stocks Appendix S1. Additional references for trait data sources 


\begin{tabular}{|c|c|c|c|c|c|c|c|c|c|c|c|c|}
\hline \multirow[b]{2}{*}{ Variable } & \multicolumn{3}{|c|}{ Total soil carbon } & \multicolumn{3}{|c|}{$\begin{array}{l}\text { Active fraction } \\
(4000-250 \mu \mathrm{m})\end{array}$} & \multicolumn{3}{|c|}{$\begin{array}{l}\text { Intermediate fraction } \\
(50-250 \mu \mathrm{m})\end{array}$} & \multicolumn{3}{|c|}{ Stable fraction $(0.45-50 \mu \mathrm{m})$} \\
\hline & $\begin{array}{r}\text { Param. } \\
\text { Est. }\end{array}$ & $\begin{array}{r}\text { AIC } \\
\text { change } \\
(\Delta \mathrm{i})^{*}\end{array}$ & $P$ value $^{*}$ & $\begin{array}{r}\text { Param. } \\
\text { Est. }\end{array}$ & $\begin{array}{r}\text { AIC } \\
\text { change } \\
(\Delta \mathrm{i})^{*}\end{array}$ & $P$ value $^{*}$ & $\begin{array}{r}\text { Param. } \\
\text { Est. }\end{array}$ & $\begin{array}{r}\text { AIC } \\
\text { change } \\
(\Delta \mathrm{i})^{*}\end{array}$ & $\begin{array}{r}P \\
\text { value }^{*}\end{array}$ & $\begin{array}{r}\text { Param. } \\
\text { Est. }\end{array}$ & $\begin{array}{r}\text { AIC } \\
\text { change } \\
(\Delta \mathrm{i})^{*}\end{array}$ & $\begin{array}{r}P \\
\text { value }^{*}\end{array}$ \\
\hline Intercept & 64.35 & & $<0.0001$ & 12.57 & & $<0.0001$ & 39.21 & & 0.0001 & 4.22 & & 0.12 \\
\hline MAP (mm) & & & 0.0001 & $-6.4 e-4$ & 14.21 & 0.0001 & & & & & & \\
\hline $\operatorname{MAP}(\mathrm{mm})^{2}$ & & & 0.0001 & $5 e-6$ & 18.71 & 0.0009 & & & & & & \\
\hline $\operatorname{MAT}\left({ }^{\circ} \mathrm{C}\right)$ & -10.72 & 14.64 & 0.025 & -2.28 & 17.99 & $<0.0001$ & -6.91 & 10.37 & 0.0008 & & & \\
\hline $\operatorname{MAT}\left({ }^{\circ} \mathrm{C}\right)^{2}$ & 0.62 & 13.23 & 0.0067 & 0.11 & 8.97 & $<0.0001$ & 0.40 & 10.81 & 0.0003 & & & \\
\hline Soil moisture (\% dry weight) & 0.035 & -3.36 & 0.0002 & & & & 0.021 & 2.05 & 0.049 & & & \\
\hline Soil moisture $(\% \text { dry weight })^{2}$ & $-1.8 \mathrm{e}-4$ & -5.36 & $<0.0001$ & & & & $-1.1 \mathrm{e}-4$ & 4.02 & 0.014 & & & \\
\hline MGSL (days) & & & & 0.010 & 4.17 & 0.013 & & & & & & \\
\hline Soil pH & -5.86 & 18.89 & & -0.99 & 5.51 & 0.0086 & -2.95 & 9.38 & 0.0012 & -1.59 & 17.57 & $<0.0001$ \\
\hline Soil $\mathrm{pH}^{2}$ & 0.52 & 11.64 & & 0.077 & 4.3 & 0.012 & 0.26 & 6.69 & 0.0032 & 0.16 & 2.35 & 0.037 \\
\hline CWM SLA $\left(\mathrm{mm}^{2} \mathrm{mg}^{-1}\right)$ & & & & -0.024 & 9.09 & 0.0009 & & & & & & \\
\hline CWM leaf $\mathrm{N}$ content $\left(\mathrm{mg} \mathrm{N} \mathrm{g}^{-}\right.$ & & & & & & & & & & 0.039 & 4.13 & 0.01 \\
\hline
\end{tabular}


function. In these cases both the main effect and the quadratic tern were removed. 
Fig. 1. Sampling regions within England. In each region five farms were selected and in each 610 of these three fields were sampled, one unimproved grassland, one semi-improved and one improved. Regions are: (a) Worcester, (b) Upper Thames, (c) Somerset, (d) Devon, (e) region (m), Northumberland, 20 fields were sampled.

Fig. 2. Fitted relationships between abiotic and plant community trait variables and grassland soil carbon stocks. In all figures the other variables in the models (Table 1) were held constant at their mean in the dataset (Table S1). Relationships are between: A) MAT and pH with total soil carbon stocks. B) MAT and mean annual precipitation with carbon in the active fraction. C) Soil $\mathrm{pH}$ and MAT with carbon in the intermediate fraction d) soil $\mathrm{pH}$ and the $\mathrm{CWM}$ of leaf nitrogen content and carbon in the stable fraction. Stocks are for the top $7 \mathrm{~cm}$ of the soil.

Fig. 3. Changes in grassland soil carbon stocks across (A) temperature and (B) soil pH gradients. MAT is mean annual temperature. The stocks shown are the three size fractions predicted by the fitted models when all other variables are held constant at their mean in the dataset (Table S1).

627 
630 Figure removed for file size reasons

$631 \quad$ Fig. 1
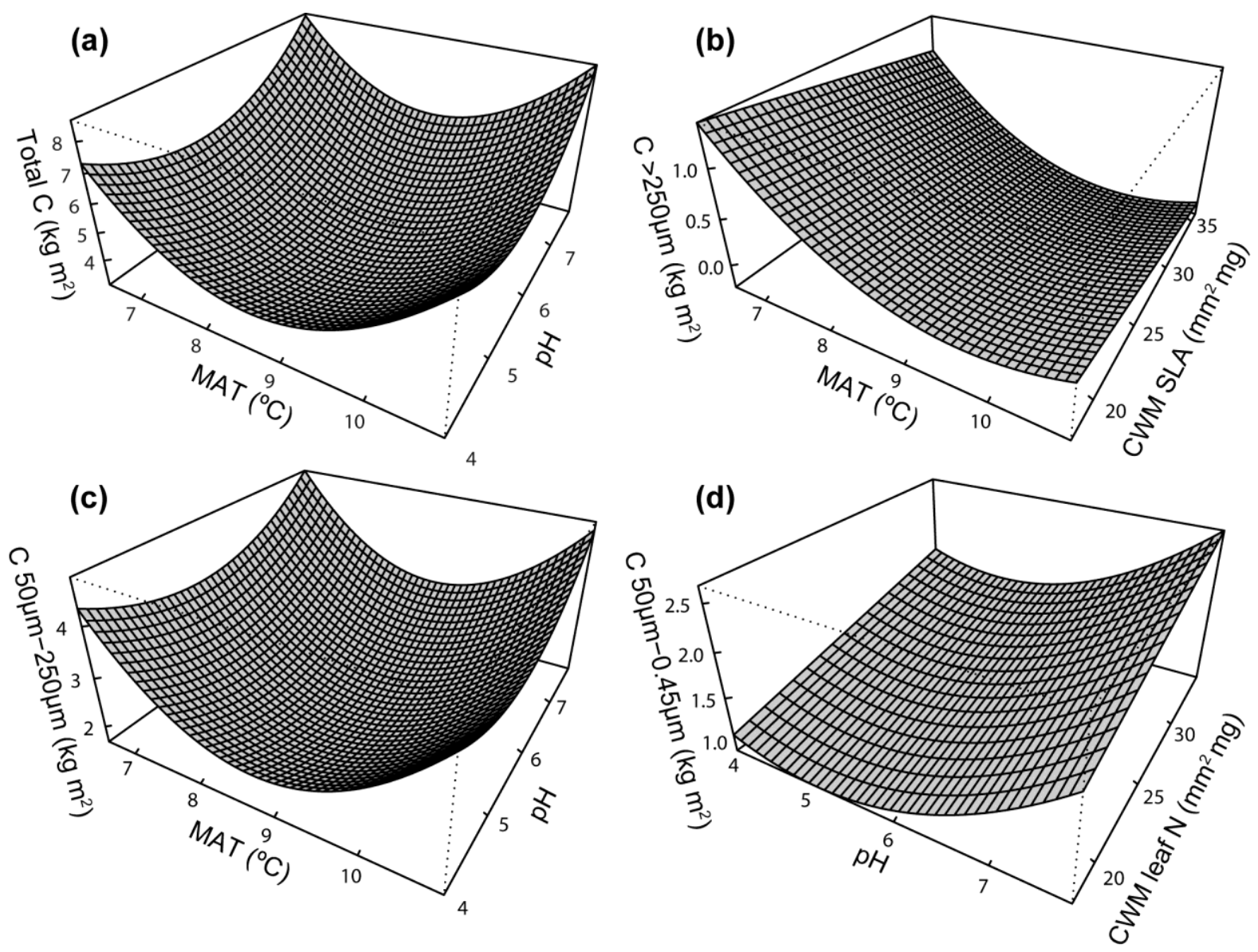

632

633 Fig. 2.

634

635

636

637

638 

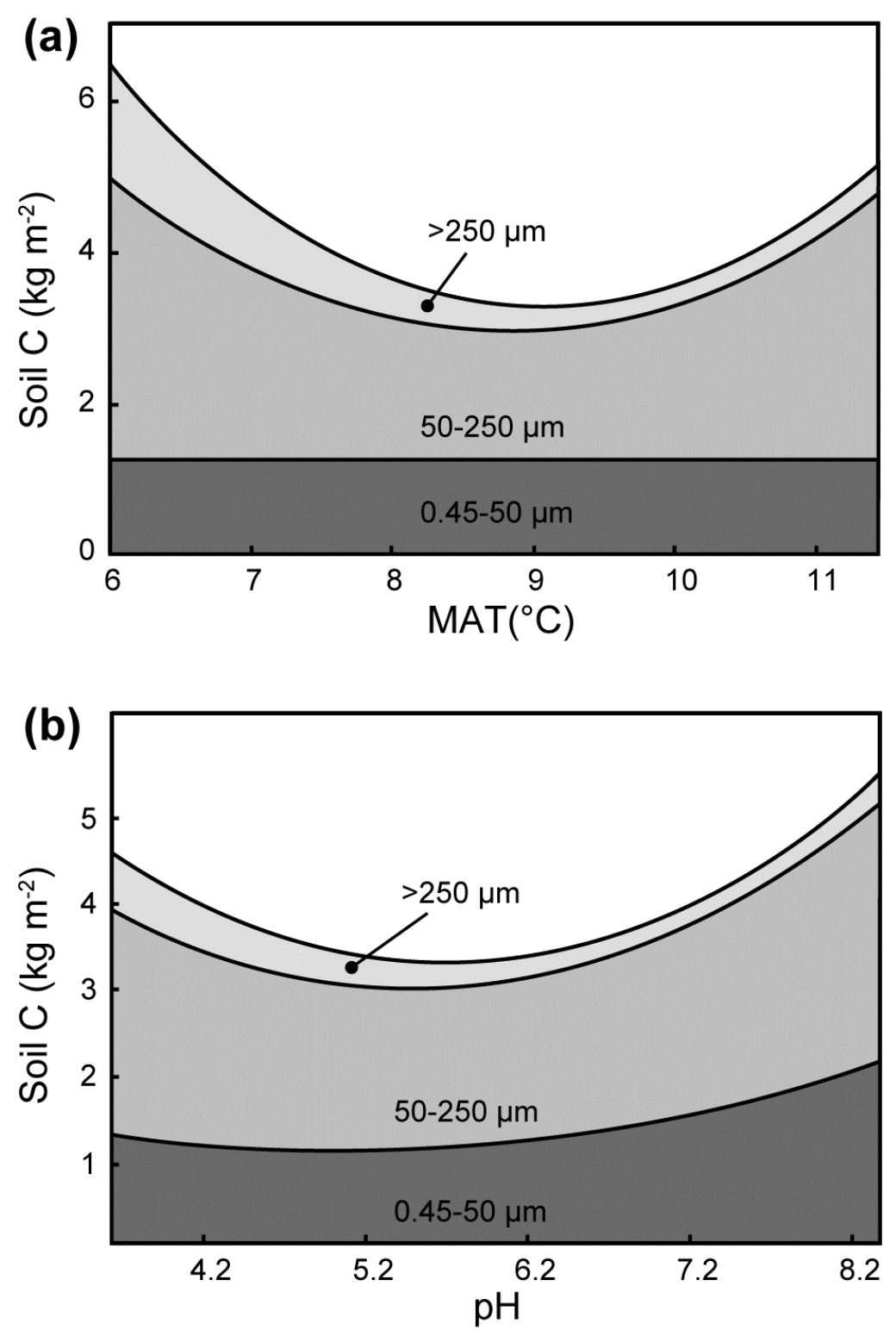

$640 \quad$ Fig. 3.

641

642

643

644 